\title{
Should we screen for masked hypertension in patient with vascular disease?
}

This article was published in the following Dove Press journal:

Vascular Health and Risk Management

7 May 2010

Number of times this article has been viewed

\section{Pascal Delsart' \\ Philippe Marboeuf' \\ Cedric Delhaye ${ }^{2}$ \\ Gilles Lemesle ${ }^{2}$ \\ Claire Mounier-Vehier \\ 'Service de Médecine Vasculaire et Hypertension Artérielle, ${ }^{2}$ Service d'hémodynamique et de Cardiologie B, University Hospital of Lille, France}

Correspondence: Pascal Delsart Service de Médecine Vasculaire et Hypertension Artérielle Hôpital Cardiologique, CHRU de Lille, Boulevard du Pr Leclercq, 59037 Lille Cedex, France Tel +330320444365

Fax +33032044 4078

Email delsartpascal@yahoo.fr
Background: The influence of hypertension on cardiovascular risk is well known. Ambulatory blood pressure measurement (ABPM) is able to identify patients with masked hypertension $(\mathrm{MH})$ underdetected by clinical BP measurement. The benefit of screening for $\mathrm{MH}$ in a highrisk population was investigated.

Aims: To detect MH in a population with no prior history of hypertension and medically treated for peripheral or coronary arterial disease.

Methods: Thirty-eight consecutive patients with peripheral or coronary artery disease documented with arteriography, without a history of hypertension, and with an admission BP $<140 / 90 \mathrm{mmHg}$ underwent ABPM after discharge. Ambulatory BP $\geq 125 / 80 \mathrm{mmHg}$ were defined as $\mathrm{MH}$

Results: MH was found in 11 patients (28.9\%). The MH group had a mean systolic and diastolic hospitalization BP significantly higher (127 versus $115 \mathrm{mmHg}$, respectively, $P=0.002$ and 76 versus $66 \mathrm{mmHg}, P=0.01$ ), and tended to have a higher admission systolic BP and pulse pressure (127 versus $121 \mathrm{mmHg}$, respectively, $P=0.07$; and 54 versus $46 \mathrm{mmHg}, P=0.06$ ). The first BP measurement on the 24-hour ABPM was significantly higher in the MH group 140 versus $121 \mathrm{mmHg}, P=0.001$, for systolic BP and 84 versus $74 \mathrm{mmHg}, P=0.03$, for diastolic BP.

Conclusions: $\mathrm{MH}$ was found in patients with documented and medically treated vascular disease. BP in the prehypertensive range is associated with MH. Systematic screening for MH in this high-risk population requires further investigation.

Keywords: blood pressure, monitoring, masked hypertension, vascular disease

\section{Background}

Arterial hypertension is a well documented risk factor in the cardiovascular disease continuum. ${ }^{1}$ Its diagnosis has traditionally relied on clinical blood pressure (BP) measurement, but ambulatory BP monitoring (ABPM) offers a new method of identifying hypertensive disease and managing its consequences.

In addition to normotensive and "classically hypertensive" patients, it is now possible to distinguish between patients suffering from "white coat" hypertension and those with masked hypertension $(\mathrm{MH})$. The definition of $\mathrm{MH}$ is $\mathrm{BP}$ values within normal limits on clinical examination which are increased during ABPM. Diagnosis of MH therefore relies on ABPM, which explains why a large portion of the population with $\mathrm{MH}$ is undiagnosed. $\mathrm{MH}$ has been recognized to have adverse consequences for patient prognosis in terms of cardiovascular morbidity, as well as target organ damage. Its prevalence varies widely depending on sources or method of BP measurement (ABPM or self-measurement) but the outcome of $\mathrm{MH}$ is important in that it concerns 
a large variety of patients, ranging from children to elderly patients, who are often already on treatment. ${ }^{2,3}$

Recent studies have shown that approximately $80 \%$ of patients suffering from vascular disease whether coronary, cerebral, or peripheral, have hypertension, ${ }^{4}$ and lowering of arterial BP favorably influences the prognosis, especially in patients with coronary lesions and those with a history of stroke. ${ }^{5,6}$

Recommendations for management of vascular patients emphasize the importance of testing and treatment for hypertension. ${ }^{7}$ However, the methods that should be used to test for it have not been well outlined, and ABPM has not yet been included in the recommendations.

The use of ACE inhibition in patients with vascular disease has been validated by many studies showing its long term benefits for patient prognosis regardless of BP values, ${ }^{8,9}$ and prescription of ACE inhibitors has become routine in vascular patients, even in those not diagnosed with hypertension.

To date there are very little data available on $\mathrm{MH}$, and it seems likely that mass screening will never be possible. However, it would be useful to determine risk factors which would raise suspicion of $\mathrm{MH}$ and thereby identify patients who would benefit from systematic testing. The purpose of this study was to confirm MH in patients with atherothrombotic vascular disease who are already on treatment, and to identify their risk factors.

\section{Methods}

\section{Study population}

We recruited patients from two wards of the Lille University Hospital Center from September 2007 to July 2008. These patients were scheduled for coronary angiography or lower limb angiography. Inclusion criteria were systolic BP (SBP) $<140 \mathrm{mmHg}$, diastolic BP (DBP) $<90 \mathrm{mmHg}$, and at least one proven vascular atherothrombotic site (defined as a stenosis $\geq 50 \%$ ). Forty-one patients gave verbal consent for ABPM testing. Due to false positive results on noninvasive ischemic testing, three patients were found to be free of atherothrombotic lesions and were therefore excluded. The 38 remaining patients were included in the study.

\section{Arterial blood pressure measurement}

Arterial BP was measured after at least 10 minutes of rest using a cuff adapted to patient size and a manual manometer. Mean BP and heart rate (HR) over the period of hospitalization was calculated using seven measurements for each patient collected by nurses using the electronic Datascope Acutor Plus device.

The participants underwent ABPM during usual everyday activity a week later while still being treated, using a Spacelab Medical 90207 monitoring device, which recorded BP every 15 minutes over a 24 -hour period divided into daytime (from $6 \mathrm{am}$ to $10 \mathrm{pm}$ ) and nighttime (from $10 \mathrm{pm}$ to $6 \mathrm{am}$ ).

Patients were then divided into two categories, ie, normotensive patients with SBP and DBP at admission $<140$ and $<90 \mathrm{mmHg}$, respectively, as well as 24-hour ambulatory mean $\mathrm{SBP}<125 \mathrm{mmHg}$ and $\mathrm{DBP}<80 \mathrm{mmHg}$, and MH patients with normal BP at admission but with 24-hour ambulatory mean SBP $>125$ and DBP $>80 \mathrm{mmHg}$. This definition of MH is based on the European Society of Hypertension and European Society of Cardiology guidelines. This low BP level has already been used in a prospective, large-scale study using ABPM in patients who had never been previously treated with antihypertensive medication. ${ }^{10}$

The only antihypertensive drugs used in this patient population with stable vascular disease were reninangiotensin inhibitors. Patients with a prior history of myocardial infarction or left ventricular ejection fraction $<55 \%$ were excluded because they required beta-blockade therapy that could have influenced the study results.

\section{Statistical analysis}

SPSS software (SPSS, Chicago, IL) was used for statistical analysis. For the descriptive analysis, we extracted the median and frequency of each parameter for the two groups. The population of each group being under 30 patients, we chose a bivariate analysis with nonparametric testing. Quantitative testing relied on comparison of means using the MannWhitney U test. Qualitative comparison of means was done using the Chi-squared test or Fisher's exact test. Statistical significance was determined at $P<0.05$.

\section{Results}

The prevalence of $\mathrm{MH}$ in our study population was $28.9 \%$ (Table 1). Of the 38 participants, 22 underwent lower limb angiography and the other 16 underwent coronary angiography. Four patients suffered from stable coronary disease diagnosed by coronary angiography during a previous hospitalization. No statistical differences between the masked hypertensive and normotensive groups were found for age, sex, or cardiovascular risk factors, nor were there any discernable differences in terms of treatment or biologic parameters. 
Table I Population characteristics, and clinical and biologic data at hospital admission

\begin{tabular}{|c|c|c|c|}
\hline Clinical and biologic data & $\begin{array}{l}\text { Normotensive group } \\
(n=27)\end{array}$ & $\begin{array}{l}\text { Masked hypertensive group } \\
(n=I I)\end{array}$ & $P$ \\
\hline Age (years, n) & $55 \pm 1.9$ & $49 \pm 2.8$ & 0.43 \\
\hline Male gender $(n)$ & 24 & 9 & 0.45 \\
\hline Cardiovascular & 10 & 3 & 0.43 \\
\hline \multicolumn{4}{|l|}{ family history (n) } \\
\hline Coronary disease (n) & 17 & 3 & 0.05 \\
\hline Peripheral artery disease (n) & 6 & 3 & 0.28 \\
\hline $\operatorname{COPD}(n)$ & 5 & 0 & 0.16 \\
\hline Current smoker (n) & 18 & 7 & 0.57 \\
\hline Dyslipidemia (n) & 17 & 3 & 0.05 \\
\hline Diabetes mellitus (n) & 3 & 2 & 0.45 \\
\hline BMI $\left(\mathrm{kg} / \mathrm{m}^{2}\right)$ & $26.3 \pm 1.5$ & $25 \pm 0.9$ & 0.38 \\
\hline \multicolumn{4}{|l|}{ Treatment before admission } \\
\hline ACE inhibitor (n) & 15 & 5 & 0.42 \\
\hline Statin $(n)$ & 20 & 5 & 0.96 \\
\hline Antiplatelet therapy (n) & 24 & 8 & 0.22 \\
\hline \multicolumn{4}{|l|}{ Biologic data } \\
\hline Creatinine (mg/L) & $9 \pm 0.3$ & $9 \pm 0.5$ & 0.78 \\
\hline GF Cockcroft (mL/min) & $103.6 \pm 6.9$ & $94.1 \pm 8.6$ & 0.49 \\
\hline GF MDRD (mL/min) & $95.9 \pm 4.2$ & $88.7 \pm 11.7$ & 0.63 \\
\hline $\mathrm{HDL}(\mathrm{g} / \mathrm{L})$ & $0.45 \pm 0.02$ & $0.46 \pm 0.03$ & 0.64 \\
\hline LDL (g/L) & $0.99 \pm 0.08$ & $1.12 \pm 0.07$ & 0.58 \\
\hline Triglyceridemia (g/L) & $1.18 \pm 0.2$ & $1.5 \mathrm{I} \pm 0.4$ & 0.29 \\
\hline
\end{tabular}

Note: Values represent mean \pm standard deviation.

Abbreviations: COPD, chronic obstructive pulmonary disease; BMI, body mass index; ACE, angiotensin converting enzyme; GF, glomerular filtrate; HDL, high-density lipoprotein; LDL, low-density lipoprotein; MDRD, modification of diet in renal disease.

\section{$B P$ at admission versus $A B P M$}

We noticed a difference, albeit not statistically significant, in BP between the two groups on admission (Table 2) and on ABPM (Table 3). MH patients seemed to have a higher mean $\mathrm{SBP}(P=0.02)$ as well as a higher mean DBP $(P=0.01)$.

The first measurement carried out by the ABPM device in the presence of a nurse is considered a clinical BP measurement and showed higher SBP $(P=0.01)$ and DBP $(P=0.03)$ in $\mathrm{MH}$ patients. We found the same significant

Table 2 Inhospital data

\begin{tabular}{llll}
\hline Inhospital & $\begin{array}{l}\text { Normotensive } \\
\text { group } \\
(\mathbf{n}=\mathbf{2 7})\end{array}$ & $\begin{array}{l}\text { Masked } \\
\text { hypertensive } \\
\text { group }(\mathbf{n}=\mathbf{I I})\end{array}$ & $\boldsymbol{P}$ \\
\hline Admission & & & \\
SBP $(\mathrm{mmHg})$ & $121 \pm 1.9$ & $127.5 \pm 2.7$ & 0.07 \\
DBP $(\mathrm{mmHg})$ & $73 \pm 1.5$ & $78 \pm 2.6$ & 0.26 \\
HR (beats per minute) & $68 \pm 2.8$ & $76.5 \pm 4.1$ & 0.19 \\
PP (mmHg) & $47 \pm 1.1$ & $51 \pm 2.9$ & 0.52 \\
Inhospital stay & & & \\
Mean SBP $(\mathrm{mmHg})$ & $115.8 \pm 1.6$ & $127.2 \pm 1.3$ & 0.002 \\
Mean DBP $(\mathrm{mmHg})$ & $66.6 \pm 1.0$ & $76.1 \pm 2.6$ & 0.01 \\
Mean PP $(\mathrm{mmHg})$ & $46.7 \pm 6.3$ & $54.5 \pm 5.9$ & 0.06 \\
\hline
\end{tabular}

Note: Values represents mean \pm standard deviation.

Abbreviations: ACE, angiotensin converting enzyme inhibitors; BMl, body mass index; COPD, chronic obstructive pulmonary disease; SBP, systolic blood pressure; DBP, diastolic blood pressure; HR, heart rate; PP, pulse pressure. difference while studying daytime SBP and DBP $(P<0.01$ and $P=0.009$, respectively) as well as nighttime SBP and DBP $(P=0.001$ and $P=0.03)$.

The same classes of antihypertensive treatment were utilized in both groups of patients during ABPM periods. SBP and DBP were once again found to be significantly higher in MH patients both during daytime $(P<0.001$ and $P=0.009$, respectively) and nighttime measurements $(P=0.001$ and $P=0.03)$.

\section{Discussion}

MH is not a well recognized illness, even though its unfavorable prognostic consequences for patients in terms of subsequent cardiovascular events has been largely accepted. ${ }^{11}$ Its influence on intermediary markers of cardiovascular risk is well known and is much the same as that of classical hypertension. Kotsis et al demonstrated that patients suffering from MH had more severe target organ damage, with a larger left ventricular mass and thicker intima media than that found in a normotensive population. ${ }^{12}$ Ohasama observed a similarly unfavorable prognosis regarding cardiovascular morbidity and mortality in people with MH. The same study recorded a statistically higher risk of cardiovascular mortality and stroke in patients suffering from masked or regular hypertension than in normotensive patients or those with "white coat" 
Table 3 Ambulatory 24-hour blood pressure monitoring data

\begin{tabular}{|c|c|c|c|}
\hline & $\begin{array}{l}\text { Normotensive } \\
\text { group }(n=27)\end{array}$ & $\begin{array}{l}\text { Masked hypertensive } \\
\text { group }(n=I I)\end{array}$ & $P$ \\
\hline \multicolumn{4}{|l|}{ ABPM } \\
\hline SBP, first measurement $(\mathrm{mmHg})$ & $|2| \pm 3.3$ & $140 \pm 3.1$ & 0.001 \\
\hline DBP, first measurement $(\mathrm{mmHg})$ & $74 \pm 1.9$ & $84 \pm 4.1$ & 0.03 \\
\hline \multicolumn{4}{|l|}{ 24-hour ABPM } \\
\hline $\mathrm{SBP}(\mathrm{mmHg})$ & $112 \pm 1.6$ & $128.5 \pm 1.3$ & $<0.001$ \\
\hline $\mathrm{DBP}(\mathrm{mmHg})$ & $67 \pm 1.0$ & $78 \pm 2.6$ & 0.02 \\
\hline HR (beats/min) & $64 \pm 2.1$ & $76 \pm 4.5$ & 0.12 \\
\hline PP $(\mathrm{mmHg})$ & $46 \pm 5.9$ & $5 I \pm 6.1$ & 0.002 \\
\hline \multicolumn{4}{|l|}{ ABPM during day } \\
\hline $\mathrm{SBP}(\mathrm{mmHg})$ & $116 \pm 1.7$ & $133.5 \pm 1.4$ & $<0.001$ \\
\hline $\mathrm{DBP}(\mathrm{mmHg})$ & $72 \pm 1.0$ & $81.5 \pm 2.8$ & 0.009 \\
\hline HR (beats/min) & $67 \pm 2.1$ & $75 \pm 4.7$ & 0.17 \\
\hline \multicolumn{4}{|l|}{ ABPM during night } \\
\hline $\mathrm{SBP}(\mathrm{mmHg})$ & $103 \pm 22.4$ & $120 \pm 2.4$ & 0.001 \\
\hline $\mathrm{DBP}(\mathrm{mmHg})$ & $6 \mathrm{I} \pm 1.4$ & $68 \pm 2.5$ & 0.03 \\
\hline HR (beats/min) & $67 \pm 2.3$ & $75 \pm 4.6$ & 0.17 \\
\hline \multicolumn{4}{|l|}{ Treatment at discharge } \\
\hline ACE inhibitors (n) & 19 & 7 & 0.80 \\
\hline Statin $(n)$ & 20 & 8 & 0.61 \\
\hline
\end{tabular}

Values represent mean \pm standard deviation.

Abbreviations: ABPM, ambulatory blood pressure monitoring; SBP, systolic blood pressure; DBP, diastolic blood pressure; HR, heart rate; ACE, angiotensin-converting enzyme; PP, pulse pressure.

hypertension. ${ }^{13}$ This is equally true in populations of patients with treated hypertension or untreated MH. ${ }^{14,15}$

When comparing MH patients with normotensive patients, we found a $15 \mathrm{mmHg}$ gap between daytime and nighttime measurements for both SBP and DBP. This difference is important when considering the linear relationship between BP values and risk of cardiovascular events, and highlights the importance of considering the existence of $\mathrm{MH}$ when optimizing treatment in patients in need of secondary prevention.

Detection of MH during routine clinical examination is impossible and requires the use of ABPM, without which MH would probably be missed in patients requiring secondary prevention, thereby allowing undiagnosed and uncontrolled high blood pressure to increase their cardiovascular risk. Divergent data make it difficult to identify a specific kind of patient more likely to suffer from MH. However, Malion et al have suggested a profile of patients at high risk, ie, men who smoke and have higher triglyceride and lower HDL levels than the general normotensive population. ${ }^{16}$ Our study could not confirm this hypothesis, mainly because of the low number of patients recruited and the predominance of male subjects.

Our work confirmed the existence of MH in a predetermined group of patients with no recorded history of hypertension but undergoing treatment with antihypertensive agents, prescribed principally for their antiatheromatous action. The existence of MH was indicated by higher BP, both during the hospitalization period and during measurement before a consultation. This phenomenon has already been described, and indicates that the cut-off values for the diagnosis of hypertension at SBP $140 \mathrm{mmHg}$ and DBP $90 \mathrm{mmHg}$ are inappropriate. This takes us in the same direction as the American guidelines for hypertension that define values for SBP of $130-139 \mathrm{mmHg}$ and $80-89 \mathrm{mmHg}$ for DBP as the prehypertensive range. ${ }^{17}$ Unfortunately, this definition seems to encompass too large a population according to data collected by the National Health and Nutrition Examination Survey (NHANES) that showed that $31 \%$ of all adults over the age of 20 had BP in the prehypertensive range. ${ }^{18}$

Diagnosing MH requires the use of ABPM, but mass testing using this method is impractical and should only be used in selected populations. Our work confirms other recent findings that patients with $\mathrm{MH}$ often have $\mathrm{BP}$ values in the upper normal range. ${ }^{19}$

The prognostic value of classifying hypertensive patients for primary and secondary prevention purposes is wellknown but the most effective diagnostic tools and the role of ABPM in this regard remain ill-defined. It seems reasonable to advocate that secondary prevention patients would benefit from ABPM because their BPs are at the upper limits of those considered to be normal according to recent European guidelines. ${ }^{20}$ 
The ideal solution would seem to be to determine other factors, whether clinical, anamnestic, or biologic, that could be used to calculate a score capable of predicting a high probability of $\mathrm{MH}$ in the same way that the prevalent score is used to determine which patients would benefit from systolic index pressure measurement. Selfmeasurement seems to be just as effective in detecting $\mathrm{MH}$ as ABPM but is more accessible, especially for general practitioners, and is more cost-effective. The optimal solution has yet to be defined and since ABPM has been the method of choice in a larger number of studies, it is more widely used. ${ }^{21}$

Our study shows a statistically significant difference between nighttime and daytime SBP and DBP. Self-measurement appears to be a more limiting tool than ABPM, one major difference being that $\mathrm{ABPM}$ simplifies measurement of nighttime BP values at regular intervals. Nighttime hypertension is a risk factor for cardiovascular events and can be responsible for target organ damage. Nocturnal hypertension can be a sign of sleep apnea syndrome. Detection of nocturnal hypertension should prompt the physician to prescribe an evening antihypertensive agent.

The main limitation of our study was its small sample size. Therefore it was not possible to assess frequency and outcomes of $\mathrm{MH}$ in a population of secondary prevention patients. However, patients with significant vascular disease, no prior history of hypertension, and free from any antihypertensive treatment (except for renin-angiotensin system inhibitors) are not so frequent in current practice. We chose to exclude patients on antihypertensive treatment at admission in order to facilitate the interpretation of results. Finally, the definition of MH is debated; we chose in the present study to use the lower range of $\mathrm{BP}$ in accordance with recent published guidelines for management of systemic hypertension. As a consequence, the results of this study should be interpreted within these limitations.

\section{Conclusion}

MH is a separate entity with very real prognostic consequences, as shown in studies comparing MH patients with normotensive patients. Its diagnosis in the setting of vascular disease appears to be necessary. Since mass testing is not practical, detection of $\mathrm{MH}$ should at the very least be undertaken in specifically targeted high-risk populations.

\section{Disclosure}

The authors report no conflicts of interest in this work.

\section{References}

1. Dzau VJ, Antman EM, Black HR, et al. The cardiovascular disease continuum validated: Clinical evidence of improved patient outcomes: Part I: Pathophysiology and clinical trial evidence (risk factors through stable coronary artery disease). Circulation. 2006;114(25): 2850-2870.

2. Bobrie G, Clerson P, Ménard J, Postel-Vinay N, Chatellier G, Plouin PF. Masked hypertension: A systematic review. J Hypertens. 2008;26(9): 1715-1725.

3. Stabouli S, Kotsis V, Toumanidis S, Papamichael C, Constantopoulos A, Zakopoulos N. White-coat and masked hypertension in children: Association with target-organ damage. Pediatr Nephrol. 2005;20(8): 1151-1155.

4. Ohman EM, Bhatt DL, Steg PG, et al; REACH Registry Investigators. The REduction of Atherothrombosis for Continued Health (REACH) Registry: An international, prospective, observational investigation in subjects at risk for atherothrombotic events - study design. Am Heart J. 2006;151(4):786.e1-e10.

5. Yap YG, Duong T, Bland JM, et al. Prognostic value of blood pressure measured during hospitalization after acute myocardial infarction: An insight from survival trials. J Hypertens. 2007;25(2):307-313.

6. Arima H, Chalmers J, Woodward M, et al; PROGRESS Collaborative Group. Lower target blood pressures are safe and effective for the prevention of recurrent stroke: The PROGRESS trial. J Hypertens. 2006;24(6):1201-1208.

7. De Backer G, Ambrosioni E, Borch-Johnsen K, et al. Third Joint Task Force of European and Other Societies on Cardiovascular Disease Prevention in Clinical Practice. European guidelines on cardiovascular disease prevention in clinical practice. Third Joint Task Force of European and other societies on cardiovascular disease prevention in clinical practice. Eur Heart J. 2003;24(17):1601-1610.

8. Weinsaft JW. Effect of ramipril on cardiovascular events in high-risk patients. N Engl J Med. 2000;342(3):145-153.

9. Fox KM. European Trial on Reduction of Cardiac Events with Perindopril in Stable Coronary Artery Disease Investigators. Efficacy of perindopril in reduction of cardiovascular events among patients with stable coronary artery disease: Randomised, double-blind, placebo-controlled, multicentre trial (the EUROPA study). Lancet. 2003;362(9386):782-788.

10. Mancia G, De Backer G, Dominiczak A, et al. ESH-ESC Task Force on the Management of Arterial Hypertension. 2007 ESH-ESC practice guidelines for the management of arterial hypertension. J Hypertens. 2007;25(9):1751-1762.

11. Mancia G, Facchetti R, Bombelli M, Grassi G, Sega R. Long-term risk of mortality associated with selective and combined elevation in office, home, and ambulatory blood pressure. Hypertension. 2006;47(5): 846-853.

12. Kotsis V, Stabouli S, Toumanidis S, et al. Target organ damage in "white coat hypertension" and "masked hypertension". Am J Hypertens. 2008;21(4):393-399.

13. Ohkubo T, Kikuya M, Metoki H, et al. Prognosis of "masked" hypertension and "white-coat" hypertension detected by 24-h ambulatory blood pressure monitoring: 10-year follow-up from the Ohasama study. J Am Coll Cardiol. 2005;46(3):508-515.

14. Bobrie G, Chatellier G, Genes N, et al. Cardiovascular prognosis of "masked hypertension" detected by blood pressure self-measurement in elderly treated hypertensive patients. JAMA. 2004;291(11):1342-1349.

15. Björklund K, Lind L, Zethelius B, Andrén B, Lithell H. Isolated ambulatory hypertension predicts cardiovascular morbidity in elderly men. Circulation. 2003;107(9):1297-1302.

16. Mallion JM, Clerson P, Bobrie G, Genes N, Vaisse B, Chatellier G. Predictive factors for masked hypertension within a population of controlled hypertensives. J Hypertens. 2006;24(12):2365-2370.

17. Chobanian AV, Bakris GL, Black HR, et al. Joint National Committee on Prevention, Detection, Evaluation, and Treatment of High Blood Pressure. National Heart, Lung, and Blood Institute; National High Blood Pressure Education Program Coordinating Committee. Seventh report of the Joint National Committee on Prevention, Detection, Evaluation, and Treatment of High Blood Pressure. Hypertension. 2003;42(6):1206-1252. 
18. Qureshi AI, Suri MF, Kirmani JF, Divani AA. Prevalence and trends of prehypertension and hypertension in United States: National Health and Nutrition Examination Surveys 1976 to 2000. Med Sci Monit. 2005;11(9):CR403-CR409.

19. Obara T, Ohkubo T, Funahashi J, Kikuya M, Asayama K, Metoki H. Isolated uncontrolled hypertension at home and in the office among treated hypertensive patients from the J-HOME study. J Hypertens. 2005;23(9):1653-1660.
20. Verberk WJ, Kessels AG, de Leeuw PW. Prevalence, causes, and consequences of masked hypertension: A meta-analysis. Am J Hypertens. 2008;21(9):969-975.

21. Pickering TG, Gerin W, Schwartz JE, Spruill TM, Davidson KW Franz. Volhard lecture: Should doctors still measure blood pressure? The missing patients with masked hypertension. $J$ Hypertens. 2008;26(12):2259-2267.

\section{Publish your work in this journal}

Vascular Health and Risk Management is an international, peerreviewed journal of therapeutics and risk management, focusing on concise rapid reporting of clinical studies on the processes involved in the maintenance of vascular health; the monitoring, prevention and treatment of vascular disease and its sequelae; and the involvement of metabolic disorders, particularly diabetes. This journal is indexed on PubMed Central and MedLine. The manuscript management system is completely online and includes a very quick and fair peer-review system, which is all easy to use. Visit http://www.dovepress.com/ testimonials.php to read real quotes from published authors.

Submit your manuscript here: http://www.dovepress.com/vascular-health-and-risk-management-journal 